\title{
VANTAGENS COMPETITIVAS COM SOFTWARES LIVRES: \\ o caso de uma instituição de ensino
}

\section{1- Luciana Helena Crnkovic*}

Doutoranda pela Universidade Nove de Julho - UNINOVE, São Paulo/SP, Brasil.

Professora da Universidade Camilo Castelo Branco - Unicastelo, São Paulo/SP, Brasil.

crnkovic20@yahoo.com.br

http://lattes.cnpq.br/8815848309767756

\section{2- Sergio Luiz do Amaral Moretti}

Doutor em Ciências Sociais pela Pontifícia Universidade Católica de São Paulo, São Paulo/SP, Brasil.

Professor do Programa de Mestrado e Doutorado em Administração - PMDA, da Universidade Nove de Julho UNINOVE, São Paulo/SP, Brasil.

sergiomoretti@uol.com.br

http://lattes.cnpq.br/1686957518540720 


\title{
VANTAGENS COMPETITIVAS COM SOFTWARES LIVRES: o caso de uma instituição de ensino
}

\section{RESUMO}

O objetivo deste trabalho é investigar o processo de migração de softwares proprietários para softwares livres - SLs em um sistema de informação - SI em uma pequena empresa, no caso, uma instituição de ensino médio. O SI é um recurso fundamental e independe do porte ou ramo de atividade da empresa. Seu bom gerenciamento pode ser capaz de potencializar processos, gerar conhecimento e criar vantagens competitivas importantes. Contudo, o alto custo da aquisição de softwares proprietários é um grande obstáculo para sua implantação abrindo uma boa oportunidade de mercado para o SL, opção gratuita e com bom desempenho. Para investigar o processo de migração para SLs foi conduzido estudo de caso em uma cooperativa de ensino médio na qual pode-se observar o crescimento da importância do SI em sua operação. Na empresa em questão pode-se identificar, após a implantação dos SLs, um aumento da sinergia interdepartamental, maior dinamismo nas atividades por conta da eficiente obtenção das informações, e maior confiabilidade no SI no que se refere à segurança. No que se refere aos SLs pode-se observar claramente sua competitividade frente aos softwares proprietários.

\section{Palavras-Chave}

tecnologia da informação; sistema de informação; software livre;

\section{COMPETITIVE ADVANTAGES IN FREE SOFTWARE: THE CASE OF AN EDUCATIONAL INSTITUTION}

\begin{abstract}
The objective of this study is to investigate the migration of proprietary software to free software - FS in an small businesses information system - SI, an institution of higher education. The SI is a key resource an is independent of size or area of the company activity. Its appropriated management may be able to improve process, generate knowledge and create significant competitive advantages. However, the high cost of purchasing proprietary software is a major obstacle to their deployment by opening a good market opportunity for FSs with free choice and good performance. To investigate the migration process for FSs was conducted a case study in a cooperative school in which we can observe the growing importance of IS in its operation. The results identified after the implementation of the FSs was increased interdepartmental synergy, greater dynamism in the activities due to the efficient capture of information, and greater reliability in SI with respect to safety. In the case of FS, we can see clearly its competitiveness against the proprietary software
\end{abstract}

\section{Keywords}

Keywords: information technology; information system; free software 


\section{Introdução}

A informação é um recurso fundamental das empresas, independentemente de porte ou ramo de atividade. Sua forma é variável, mas comumente apoiada em tecnologias diversas de hardwares e softwares. A Tecnologia da Informação - TI surgida no século passado tem mantido ritmo crescente de desenvolvimento sendo impossível, com exceção das empresas com atividades específicas e simplificadas, encontrar uma organização que não seja dependente dela (MATTOS; GUIMARÃES, 2005). De fato, a maioria das empresas entraria em colapso sem um suporte de TI.

Nesse contexto, a discussão sobre os prós e contras de adotar tecnologia deixou de ser relevante. De acordo com Lucas, Swanson e Zmud (2007), se a pesquisa nos anos 70 se ocupava com os problemas de implementação, o momento atual exige viabilizar o melhor retorno dos altos investimentos em TI (MATTOS; GUIMARÃES, 2005). Assim, o gerenciamento da informação ganha importância crucial, não só por envolver - trabalho de muitas pessoas e recursos como pela capacidade de dinamizar processos, gerar conhecimento, e consequentemente criar vantagem perante a concorrência (KUSTER, 2001).

Uma alternativa econômica que ganhou força entre os recursos de TI é a utilização de Sls, recurso cada vez mais adotado por pessoas, empresas e governos em todo o mundo. Os SLS, além de serem gratuitos oferecem maior liberdade que os programas proprietários nos aspectos de modificação, distribuição e utilização. Vistos inicialmente com desconfiança pelas empresas, hoje estão tornando os sistemas de informação mais velozes, personalizados, estáveis, e a um custo próximo a zero (FGV, 2005; MATTOS; GUIMARÃES, 2005; OLIVEIRA; CASTRO, 2008).

A empresa escolhida para buscar evidências empíricas da utilização de SL foi uma cooperativa de educação que atende cerca de 300 alunos da educação infantil ao ensino médio. O sujeito da pesquisa vem de um processo de informatização desde sua fundação em 1998 quando contava com apenas um computador na secretaria da escola. Ao construir um novo prédio alguns anos depois foi montada a sala de informática, adquirido um computador para a biblioteca e os computadores foram interligados em uma rede comum. A partir deste ponto o sistema não parou de crescer assim como os custos, o que levou a empresa a buscar alternativas mais viáveis para manter a necessária expansão. Este trabalho objetiva ampliar o entendimento sobre o tema e analisar implicações e resultados da implantação de SL em pequenas empresas.

A pergunta que orienta a pesquisa é: Os SL podem melhorar a eficiência dos sistemas de TI a um custo baixo? Outros questionamentos buscam solucionar objetivos secundários, tais como: Até que ponto esses programas são confiáveis? Seu desempenho pode ser superior a um software que normalmente demanda alto investimento? Esse cenário livre está realmente pronto para entrar nas organizações? Sobre quais processos esses softwares podem operar? Buscou-se responder a essas questões por meio de duas análises: a viabilidade de gerenciar a informação através do software livre (1), e através dessa verificar a possibilidade de utilizar o software livre em todo o âmbito organizacional (2).

O trabalho está estruturado com uma revisão da literatura, a seguir a metodologia de estudo de caso utilizada, os resultados e discussão e as considerações finais do estudo.

\section{Revisão da Literatura}

Há boa literatura disponível a respeito da informação utilizada para efeitos administrativos, porém pouca no que se refere ao gerenciamento de seu processo como um todo. Os trabalhos tratam basicamente de $\mathrm{TI}$, informação, fluxo de informação, e poucos englobam o gerenciamento completo da mesma. A respeito do SL, ainda é necessário avaliar a quantidade de material disponível on line e gratuito, e uma boa parte de material prático, se não na forma de artigos e teses, mas pelo menos na forma de relatos de implementações bem-sucedidas.

A pesquisa bibliográfica permitiu constatar a importância para a empresa, da informação íntegra e veloz. Os benefícios são abrangentes e incidem na eficiência de toda a organização. Para Boar (2002) a TI tem sido historicamente utilizada para dar eficiência a ela, deixando de ser um mero meio de automatizar atividades para ser base de todo um sistema de informações, hoje indispensável e dando forma para a estrutura organizacional. Observa-se também que o completo gerenciamento da informação tem pouca relevância nas organizações brasileiras. Fica claro que o gerenciamento acontece, mas dificilmente 
abrangem-se todos os passos que o compõe, tornando o ciclo interrupto. Como a informação é inerente à empresa, o gerenciamento acontece de forma empírica e sem método (SORDI, 2003; SANTOS, 2008).

Neste contexto, na maioria das vezes não há um projeto integrado para a implantação de SI, está, é em grande parte resultante dos custos decrescentes da computação, da digitalização de toda e qualquer informação - seja áudio, vídeo, imagem ou dados - e da disponibilidade de comunicação por banda larga. A tecnologia encurta as distâncias, aumenta o nível de informação, promove o crescimento econômico e dá abertura para a nova economia do conhecimento. (BOAR, 2002; TAKAHASHI, 2000; MATTOS; GUIMARÃES, 2005). Observa-se que dados geram informações e consequentemente conhecimentos, importantes para que os gerentes tomem decisões eficazes, eficientes e efetivas. Assim, a informação é fator chave de auxilio do processo decisório, cuja tomada de decisão é feita através do conhecimento que ela propicia. (BIO, 1985; MATTOS; GUIMARÃES, 2005; OLIVEIRA, 1999; SORDI, 2003).

Normalmente a aplicação de sistema ocorre em diferentes níveis hierárquicos da empresa, quanto mais alto o nível hierárquico, mais abrangente e global deve ser a informação. Subentende-se, portanto que para todos os departamentos da empresa devem existir informações específicas com as características claras e com finalidade própria. Os processos executados dentro da empresa, desde as atividades mais simples e restritas até as mais complexas que se estendem ao todo da organização, devem fazer parte desse sistema informatizado, recebendo e gerando informações, contando com o envolvimento e comprometimento de todos os envolvidos (BIO, 1985; SANTOS, 2008; SORDI, 2003).

A informação oferece à empresa melhorias no posicionamento para a tomada de decisões, no desempenho nas tarefas rotineiras, no controle interno das operações, no atendimento ao cliente, na capacidade de reconhecer problemas proativamente, e no processo produtivo como um todo (CRUZ, 1998). Assim, as empresas capazes e preparadas para crescer globalmente podem ser consideradas organizações estruturadas e com alto grau de maturidade em seus processos (BRUNER; RAWI, 2005; KÜSTER, 2001). Nos tempos atuais, em que aproximadamente $80 \%$ dos processos de negócio dentro dessas organizações são suportados por alguma solução de tecnologia, demanda-se cada vez mais que a área de TI caminhe em parceria com as demais áreas da empresa e as principais atividades de planejamento. No entanto, trata-se de um investimento alto, e nem todas as organizações têm condições de realizá-lo buscando-se assim, alternativas inovadoras, com menor custo, mas não menos competitivas.

O surgimento dos SL tornou possível identificar uma alternativa de substituição aos softwares proprietários; como outros ao redor do mundo o próprio governo brasileiro adotou os SL o que vem trazendo economia considerável aos cofres públicos, economia essa apurada como principal razão para adoção de tal sistemática (SANTOS, 2008). Uma forma de diferenciação entre softwares, cujo contexto motiva esse artigo, diz respeito à forma como eles são desenvolvidos e distribuídos. De acordo com a Free Software Foundation (2008) ao se conceituar software livre não se deve pensar em preço, mas sim em liberdade. Um programa é livre quando oferece ao usuário quatro liberdades segundo esta fundação:

Liberdade 0 - A liberdade de executar o programa, para qualquer propósito;

Liberdade 1 - A liberdade de estudar como o programa funciona, e adaptá-lo às suas necessidades. O acesso ao código-fonte é um pré-requisito para esta liberdade;

Liberdade 2 - A liberdade de redistribuir cópias de modo que você possa ajudar ao seu próximo;

Liberdade 3 - A liberdade de aperfeiçoar o programa, e liberar os seus aperfeiçoamentos, de modo que toda a comunidade se beneficie. O acesso ao código-fonte é um pré-requisito para esta liberdade.

Sem tais liberdades, o software que é comprado e protegido contra cópia e distribuição é chamado proprietário. Porém, alguns softwares ficam entre essas duas denominações, conseqüência de inúmeros tipos de licença. Segundo Meyer et al. (2000) o software proprietário, ou comercial, é comprado normalmente com uma licença que proíbe cópia e distribuição, e permite instalação em apenas um computador, demandando um gasto maior com licenças no caso de uma empresa. Outro tipo é o programa shareware, que funciona gratuitamente, mas com restrições, em um regime de amostra, possibilitando experimentar antes de comprar a versão completa. Por fim, a distribuição freeware que é muitas vezes confundida como sendo um software livre, quando na verdade se trata apenas de um software gratuito, mas que não atende às quatro liberdades definidas pela Free Software Foundation, e muitas vezes cuja licença não permite o uso gratuito de modo comercial, isto é, em empresas. 
Normalmente os SL são, segundo GNU (2008), distribuídos sobre a licença GPL (Genera/ Public Licence), que garante as quatro liberdades básicas do software livre e orienta a respeito de cópia e distribuição. Originalmente a GPL foi escrita para o projeto GNU, um sistema operacional livre, em 1989. Os desenvolvedores a utilizam porque, apesar de garantir liberdade para o programa criado, limita sua cópia e distribuição de forma a não dar margem a um terceiro transforma-lo em proprietário. Entre diversos pontos, a licença GPL obriga a creditar o desenvolvimento do software ao responsável, assim como as alterações do mesmo, a disponibilizar o código-fonte do programa, e a não cobrar do usuário valor algum pela utilização. A Free Software Foundation não permite traduções, pois acredita que tal ação pode alterar o sentido da licença, mas aceita que as tais sejam feitas e disponibilizadas com o intuito de auxiliar a compreensão da GPL.

Segundo o GUIA LIVRE (2005) não há diferença de arquitetura, funcionalidade ou substância técnica entre o software livre e o software proprietário, porém a filosofia do software livre aparece como incentivadora à disseminação do conhecimento, conseqüente da relação diferenciada entre quem produz o software e o uso da tecnologia. Ainda segundo o GUIA é possível enumerar várias razões para a migração de sistemas proprietários para livres:

- Eliminação de mudanças impostas periodicamente pelos modelos proprietários;

- Independência de fornecedor único;

- Possibilidade de auditabilidade dos sistemas;

- Alto nível de segurança;

- Desenvolvimento do conhecimento local;

- Independência tecnológica;

- Fim das despesas referentes à licença de uso.

O quadro dá uma posição dos SLs relacionados como opções para o plano de migração do sistema de informações do Exército Nacional, sua aplicação e localização na internet.

Quadro 1 - Aplicativos de software livre que também são gratuitos

\begin{tabular}{|c|c|c|}
\hline Categoria & Nome do software & Onde encontrar na internet \\
\hline \multirow{13}{*}{ Sistema Operacional } & Conectiva Linux & http://www.conectiva.com.br \\
\hline & Debian & http://www.debian.org \\
\hline & Fedora Red Hat & http://fedora.redhat.com \\
\hline & FreeBSD & http://www.freebsd.org \\
\hline & Gentoo & http://www.gentoobr.org \\
\hline & GNU/Linux & http://www.linux.org \\
\hline & Kalango & http://www.kalangolinux.org \\
\hline & Kurumin & http://guiadohardware.net/kurumin \\
\hline & Mandrake & http://www.mandrake.com \\
\hline & OpenBSD & http://www.openbsd.org \\
\hline & Red Hat & http://www.redhat.com \\
\hline & Slackware & http://www.slackware.com \\
\hline & SuSE Linux & http://www.suse-brasil.com.br \\
\hline Servidor de Internet & Apache $\left(^{*}\right)$ & http://www.apache.org \\
\hline \multirow{3}{*}{ Pacote de Escritório } & AbiWord & http://www.abiword.org \\
\hline & Koffice & http://www.kde.org \\
\hline & OpenOffice.org (*) & http://www.openoffice.org.br \\
\hline Programa Gráfico & $\operatorname{GIMP}\left({ }^{*}\right)$ & http://www.gimp.org \\
\hline \multirow{4}{*}{$\begin{array}{l}\text { Navegador } \\
\text { internet }\end{array}$} & Galeon & http://www.galeon.org \\
\hline & Konqueror & http://www.kde.org \\
\hline & Mozilla (*) & http://www.mozilla.org \\
\hline & Opera $(*)$ & http://www.opera.com \\
\hline \multirow{2}{*}{$\begin{array}{ll}\text { Linguagem } & \text { de } \\
\text { Programação } & \end{array}$} & Perl & http://www.perl.com/download.csp \\
\hline & PHP & http://www.php.net/downloads.php \\
\hline \multirow{3}{*}{ Cliente de e-mail } & Evolution & http://www.ximian.com/products/evolution \\
\hline & Kmail & http://www.kde.org \\
\hline & Mozilla Mail $(*)$ & http://www.mozilla.org \\
\hline $\begin{array}{l}\text { Serviços de Rede para } \\
\text { Servidores }\end{array}$ & Samba & http://www.samba.org \\
\hline
\end{tabular}

Os aplicativos rodam sobre ambiente Linux.

(*) possuem versões para ambiente Windows.

Fonte: Guia Livre (2005, p. 254). 
Com a popularização do SL, migração tornou-se um termo bem conhecido. A substituição de sistemas proprietários por seus equivalentes livres é alvo de discussão, buscam-se metodologias e, por mais que se procure livros e guias, não há uma maneira padronizada de executá-la. Ao se falar em migração, deve-se entender que mudar sistemas, alterar soluções e plataformas são tarefas complexas. A migração vai além da inserção dos novos programas no sistema de informação, ela exige do administrador esforço para a mudança da cultura organizacional.

Segundo o Guia Livre (2005) a migração dos softwares proprietários para os SL deve ser vista como qualquer outra migração de sistemas de TI. Existe apenas uma peculiaridade, que é o cuidado em diferenciar a migração em servidores, da migração em estações de trabalho; no primeiro caso o SL já é aplicado em larga escala e as soluções são bem estáveis, no segundo caso requer uma busca mais complexa visando a compatibilidade com os aplicativos proprietários. Porém, é nas estações de trabalho que as grandes empresas encontram maior economia quanto aos custos de software.

O processo de migração que envolve o desligamento do software proprietário para uso exclusivo de um SL envolve uma série procedimentos. É possível encontrar guias que se propõem a isso, com exemplos de estudos de caso e metodologias. Algumas empresas obtiveram sucesso unificando esses guias e adaptando-os, como recomendados nos próprios guias, à realidade da empresa. Alencar (2007) estudou o Instituto Paulo Freire, que utilizou do Plano de Migração do Exército Brasileiro, o Plano de Migração do Ministério do Planejamento, o Guia Livre do Governo Federal, o IDA Open Source Migration Guidelines, o Plano de Migração da Secretaria de Logística e TI do Governo Federal, e o Plan Nacional de Migración a Software Libre da Venezuela, criando assim sua própria metodologia, descrita como pedagogia de migração. De acordo com o autor algumas fases devem ser observadas.

Quadro 2 - Metodologia da Pedagogia de Migração, por Alencar (2007)

\begin{tabular}{|c|c|}
\hline \multicolumn{2}{|c|}{ Primeira fase: sensibilização e construção democrática } \\
\hline Sistema operacional em uso & Windows (proprietário); \\
\hline Navegador web em uso & Internet Explorer (proprietário); \\
\hline Pacote de escritório em uso & Microso ft Office (proprietário); \\
\hline Ações com as pessoas & $\begin{array}{l}\text { Os usuários devem assumir o papel sujeitos ativos, comprometidos. A } \\
\text { equipe será responsável por planejar o processo de migração e criar } \\
\text { tutoriais dando suporte ao novo sistema livre. O planejamento deve ser } \\
\text { aberto a toda a empresa, mostrando a todos o objetivo da migração. }\end{array}$ \\
\hline \multicolumn{2}{|c|}{ Segunda fase: aprendizagem e avaliação } \\
\hline Sistema operacional em uso & Windows (proprietário); \\
\hline Navegador web em uso & Internet Explorer (proprietário) e Mozilla Firefox (livre); \\
\hline Pacote de escritório em uso & Microsoft Office (proprietário) e BrOffice.org (livre); \\
\hline Ações com as pessoas & $\begin{array}{l}\text { A partir desta fase há possibilidade de utilização de duas alternativas livres, } \\
\text { rodando sobre um ambiente ainda proprietário, dando segurança ao } \\
\text { usuário. Observando com qual programas as pessoas estão trabalhando } \\
\text { trará à equipe de migração a certeza de passar para o próximo passo. }\end{array}$ \\
\hline \multicolumn{2}{|r|}{ Terceira fase: ruptura } \\
\hline Sistema operacional em uso & Windows (proprietário); \\
\hline Navegador web em uso & Mozilla Firefox (livre); \\
\hline Pacote de escritório em usow & BrOffice.org (livre); \\
\hline Ações com as pessoas & $\begin{array}{l}\text { São desinstalados os softwares proprietários e as informações são } \\
\text { totalmente migradas para o software livre. Os usuários terão de estar aptos } \\
\text { a utilizar as duas ferramentas livres e devem ser preparados para a } \\
\text { mudança mais radical, nesse caso do sistema operacional, pois é inviável } \\
\text { manter dois sistemas operacionais diferentes } \\
\text { funcionando na mesma máquina. }\end{array}$ \\
\hline \multicolumn{2}{|r|}{ Quarta fase: migração } \\
\hline Sistema operacional em uso & Linux Ubuntu ou Kubuntu (livre); \\
\hline Navegador web em uso & Mozilla Firefox (livre); \\
\hline Pacote de escritório em uso & BrOffice.org (livre); \\
\hline Ações com as pessoas & $\begin{array}{l}\text { Última fase da migração na qual é preciso dar todo o suporte ao usuário, } \\
\text { principalmente a garantia da posse dos dados. Tem-se por vantagem que a } \\
\text { mudança foi gradual e bem aceita, e normalmente não existirá - ou haverá } \\
\text { em menor proporção - resistência quanto ao software livre. }\end{array}$ \\
\hline \multicolumn{2}{|r|}{ Quinta fase: avaliação } \\
\hline Sistema operacional em uso & Linux Ubuntu ou Kubuntu (livre); \\
\hline Navegador web em uso & Mozilla Firefox (livre); \\
\hline Pacote de escritório em uso & BrOffice.org (livre); E \\
\hline Ações com as pessoas & $\begin{array}{l}\text { Realizada a migração, é hora de levantar os pontos de sucesso e } \\
\text { insucesso. O contato com o usuário é fundamental, na forma como a } \\
\text { empresa achar conveniente, e como foi mais efetivo ao longo da migração. }\end{array}$ \\
\hline
\end{tabular}

Fonte: Adaptado pelos autores de Alencar (2007). 
Para o caso deste estudo é preciso analisar como estas migrações podem ser realizadas por instituições de ensino que lidam com grandes quantidades de informações e necessidades de pesquisas na internet e banco de dados. Segundo Oliveira e Castro (2006) baseados em trabalho na Universidade Metodista de São Paulo observou-se que um dos problemas era da escassez de espaço físico, que demandaria altos valores para ampliação do prédio da instituição e criação de novas salas. Por um valor muito inferior - estima-se que houve economia na ordem de $\mathrm{R} \$ 1.350 .000,00$ (um milhão, trezentos e cinqüenta mil reais) - foi adquirido o software francês ADESOFT, utilizado por empresas de grande porte para análise, simulação e gerenciamento do ambiente. O programa foi capaz de receber informações sobre docentes, turmas, espaço e recursos, e organizar a utilização do espaço existente e, horários de funcionamento.

Ainda segundo os autores, a tecnologia para uma instituição educacional é uma realidade obrigatória devido à concorrência acirrada nesse meio. A tecnologia em si não traz diretamente benefícios para a empresa, mas sim o seu uso aliado como meio de alcançar objetivos, estrategicamente (MEYER; BABER; PFAFFENBERGER, 2000). Nada impede a utilização de tecnologia empregada em outros segmentos, pois, por mais diferente que esse segmento possa parecer diante às indústrias ou comércios, uma grande número das necessidades são parecidas. Eles concluem que um sistema de informação eficiente é uma exigência para as instituições de ensino que querem ficar no mesmo patamar que a concorrência, mas se bem desenvolvido possibilita a criação de diferenciais competitivos (PEREIRA; 2003; OLIVEIRA; CASTRO, 2006).

Deve ser considerada também, a importância da tecnologia na educação propriamente dita. O uso dos computadores no aprendizado resume-se em programas para editar textos, fazer figuras ou brincar. Algumas escolas com propostas específicas utilizam softwares especiais para o aprendizado, mas a totalidade, incluindo essas, possui uma base tecnológica como descrita acima. O grande diferencial acaba sendo a informação que o computador possibilita absorver através do correto uso da internet; nas salas de informática das escolas os computadores atuam como portais onde a curiosidade dos alunos pode ser atendida. Assim, diante dessas necessidades básicas, o software proprietário acaba se tornando um empecilho, pelo alto custo e pela necessidade de constante substituição do hardware, já que os softwares proprietários atualizam-se ciclicamente exigindo mais recursos (MACAN; ALMEIDA, 2000).

Neste contexto, software livre aparece como alternativa justamente pela simplicidade exigida: o sistema operacional Linux e qualquer navegador de internet livre satisfazem as necessidades sem gastar um centavo. Por serem mais leves que as ferramentas proprietárias, os computadores não precisam ter uma configuração avançada, podendo dar sobrevida a computadores defasados e economizando mais ainda em hardware. Computadores defasados que são, muitas vezes, considerados lixo por grandes empresas que não sabem para onde destinar seu lixo eletrônico. Afinal de contas, quando se trata em uma sala de informática para os alunos, se prima por ter vários computadores em bom estado do que apenas um de última geração. Há de se pensar em ajustes para conciliar o comum uso do software proprietário na sociedade. O choque entre o que se vê na escola e o que se encontra no mercado de trabalho (MEYER; BABER; PFAFFENBERGER, 2000). Fases observadas de acordo com o autor.

Deve-se destacar também a atuação do governo mexicano que informatizou entre 20.000 e 30.000 laboratórios anualmente entre os anos de 2000 e 2005. O custo para utilização do software proprietário seria de aproximados 124 milhões de dólares; com o software livre, o custo é nulo, sendo que se for necessária à distribuição desses softwares por CD, avalia-se apenas o custo da gravação e da própria mídia (MACAN; ALMEIDA, 2000).

\section{Metodologia}

O método adotado para a pesquisa foi o estudo de caso, pois, como argumenta Gil (1999) ele é caracterizado pelo estudo profundo e exaustivo de um ou de pouco objetos, de maneira a permitir seu conhecimento amplo e detalhado, pois esse estudo pretendeu avaliar a eficiência da utilização de softwares livres como sistema de informação de uma instituição de ensino através. A aplicação conduziu-se de acordo com a concepção de Yin (2001): um estudo empírico que investiga um fenômeno atual dentro de seu contexto de realidade, quando as fronteiras entre o fenômeno e o contexto não são claramente definidas e no qual são utilizadas várias fontes de evidências.

Para realizar a pesquisa foi adotada a observação participante que implica em um processo longo. Em um primeiro momento negociou-se a entrada em todas as áreas e disponibilização das informações 
relevantes na cooperativa de ensino. A contrapartida desta abertura foi que a pesquisa reverteria para a cooperativa de ensino na forma de sugestões de modificações, caso houvesse. Seguiu-se uma fase exploratória, essencial para o desenvolvimento ulterior da pesquisa. O tempo é também um pré-requisito para os estudos, pois envolve o comportamento e a ação do grupo de pessoas envolvidas. Deve-se manter a observação por um longo período e não num único momento (WHYTE, 2005, p. 320).

Assim, a escolha da metodologia derivou da necessidade de se analisar em detalhes os processos, implantação e funcionamento dos SL. A empresa possui um sistema informatizado sólido, disposição para constante aquisição de tecnologia e pessoal capacitado e aberto a mudanças. Manteve um crescimento constante desde 1998 chegando nos dia atuais a uma configuração que conta com uma rede de quatro computadores em três departamentos diferentes, desempenhando funções diversas independentes do departamento em que estão. Nesse ano de 2008 foi adquirido um notebook para o uso da administração, e instalada uma rede wireless para acesso à internet por qualquer equipamento dentro da empresa.

O protocolo da pesquisa foi estruturado de forma a utilizar três formas de coleta de dados: entrevistas semi-estruturadas, observação participante e análise de documentos. As entrevistas foram realizadas com funcionários chaves responsáveis pela administração da instituição de ensino e pela Tl, por meio de um roteiro semi-estruturado com perguntas abertas, construído com base no referencial teórico, contendo 12 questões. A análise de conteúdo das entrevistas possibilitou conhecer em detalhes o ambiente da empresa e as necessidades específicas que poderiam ser atendidas pelo uso do SL.

\section{Principais Resultados}

Os principais problemas observados na pesquisa foram relacionados ao SI da cooperativa como recepção e doação de arquivos de diferentes formatos entre diferentes máquinas na rede, e proteção aos dados armazenados nessa estrutura. A observação participante permitiu perceber que a instituição de ensino continua mantendo atividades que poderiam ser otimizadas por meio de softwares mais eficientes. No contexto inicial analisado, a empresa apresentou baixo desempenho no modo como a informação é gerada, distribuída, obtida, sustentada e armazenada. Cada computador da rede possuía até então os softwares padrões para o funcionamento de qualquer micro, e as atividades eram executadas obrigatoriamente neles. Não havia programas específicos destinados às necessidades da empresa, com exceção do programa base que administra discentes e dados relacionados.

A análise aprofundada da operação tornou possível apurar que havia:

- Utilização deficiente da rede, sendo que a troca de informação entre os computadores na forma de arquivos era insuficiente ou inexistente, e quando existia era massificada a todos os usuários, independente da relevância e da confidencialidade a certo departamento;

- Existência de diferentes programas antivírus, alguns desatualizados, o que poderia gerar uma brecha na segurança da rede como um todo;

- Inexistência de cópias de segurança, uma prevenção para o caso de informações que se perdem por conseqüência de problemas técnicos, de utilização indevida dos usuários, de ataque de pragas virtuais ou mesmo do meio físico, como um incêndio, por exemplo:

- Descontrole quanto ao acesso dos dispositivos móveis à rede sem fio.

Enfim, como seria em uma organização de grande porte o fluxo de informação, o armazenamento e a infra-estrutura eram problemas a serem checados e estudados, porém com um fator considerável como agravante: um número maior de usuários do que de máquinas, fazendo com que a secretaria, a biblioteca e o laboratório de informática se tornassem centros onde todos os trabalhos dependentes da informática aconteciam. A manutenção dos equipamentos da organização era feita por uma empresa especializada, que fornecia provavelmente alguns softwares licenciados de forma ilegal.

A fase das entrevistas foi determinada pelo pequeno número de funcionários que lidam com a tecnologia, sete no total. Assim, optou-se por deixar que cada um emitisse sua própria avaliação; pode-se observar que apenas um entrevistado tinha conhecimento de SL, o restante conhecia programas populares como Linux, mas não sabia avaliar o que era livre ou não. Tal fato evidencia que as condições do SL não são de conhecimento público, talvez devido ao fato de que não têm ações de marketing como nos softwares proprietários. 
O gerenciamento da informação e o SL são vistos na empresa em estudo de forma muito positiva com $100 \%$ dos funcionários afirmando ser muito importante ou importante. No quesito de que partes da operação podem ser melhoradas o gráfico mostra que para os usuários é extrema a importância a tecnologia e a informação, havendo margem para execução do gerenciamento da informação. No gráfico identificam-se quais processos estão ocorrendo de forma satisfatória e quais podem ser melhorados, tornando o ciclo do gerenciamento da informação completo.

Gráfico 1 - Avaliação dos passos do gerenciamento da informação

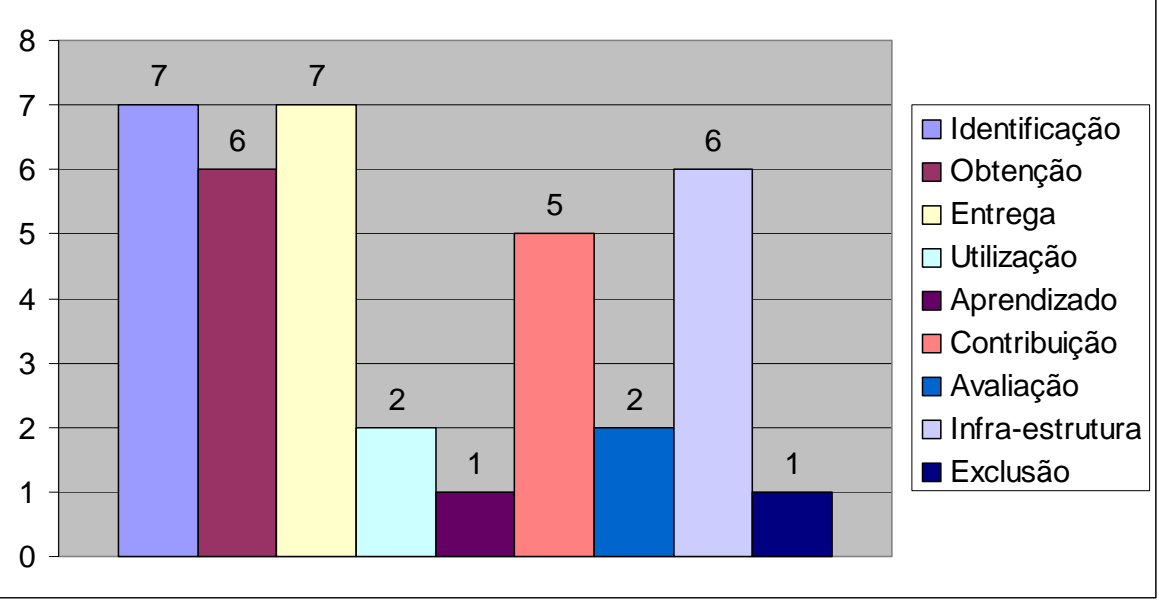

Os quatro processos com até dois votos são à primeira vista dependentes diretamente de cada usuário; é aceitável que o próprio usuário acredite ser capaz de avaliar a informação e excluí-la, por exemplo. Afinal, definir a forma como cada um utiliza e aprende com a informação, além de sua exclusão e avaliação como já citado, depende de atitudes individuais, são processos bem específicos e requerem um estudo minucioso junto a cada usuário para identificação de melhorias e alternativas.

Como foco para a proposta vindoura, destaca-se os cinco processos que receberam um número expressivo de votos. A forma como se identificam as necessidades informacionais dos usuários e como se entrega essa informação a eles são unânimes focos de desempenho insatisfatório, seguidos pela forma como se obtém informações e, próximo a eles, a contribuição de informação nesse cenário. Esses quatro aspectos resumem-se na empresa estudada como a forma como transitam as informações pela rede, a forma como se pede, entrega, disponibiliza, acessa, busca, e encontra a informação criada através de texto, dados, imagem, gráficos ou sons. Por fim, a infra-estrutura recebeu expressivos votos, com opiniões focadas na segurança e na proteção das informações, velocidade das máquinas e acesso indevido a dados confidenciais.

Quanto ao software livre, pode-se concluir que existe na equipe pesquisada a crença de que poder oferecer desempenho igual ou melhor que um software proprietário e a aceitação em migrar para um SL, com interface diferente do sistema atual, mas com mesma funcionalidade. Fica explícito que, quanto ao desempenho e ao uso, não há rejeição quanto ao fato do programa ser livre. Há grande aprovação decorrente do custo inexistente e do controle total sobre o programa. Há também desconhecimento sobre a existência de softwares livres, o que como definido no início desse capítulo resultou na abstenção dentre alguns entrevistados em emitir opinião a respeito.

\section{Discussão dos Principais Resultados}

A pesquisa na cooperativa teve a contrapartida de fornecer aos dirigentes um diagnóstico da situação que thes permitisse a melhoria do SI. Tomamos a avaliação feita como uma discussão da validade da proposta construída sobre os resultados expostos no item anterior.

Podem-se propor quatro ações capazes de suprir algumas necessidades previamente identificadas: 1) mudanças no compartilhamento de arquivos e pastas na rede; 2) execução de cópias de segurança dos arquivos e pastas importantes; 3) utilização de antivírus em toda a rede; e, 4) um sistema de chat interno com envio de arquivos. Como se esperava, todas as alternativas oferecidas foram aceitas como possíveis melhorias para o sistema empresa. Único revés por conta do chat, com um voto negativo resultado de que 
seu uso possa ser focado a conversas informais entre seus usuários, preocupação essa freqüente em diversas empresas, que depende felizmente ou infelizmente do bom-senso de cada utilizador.

Reforçou-se à instituição de ensino que fosse executada a implementação de SL que tornassem a empresa eficiente nos processos que condizem a gerenciar a informação de forma satisfatória. Foram utilizadas opções que suprissem os cinco processos que apresentam desempenho insatisfatório e que incidem sobre todos os departamentos da organização, tornando assim o ciclo do gerenciamento da informação completo. São eles: identificar as necessidades de informação, obter informação, distribuir a informação, contribuir com a geração da informação, e construir e sustentar a infra-estrutura.

Embasado na pesquisa bibliográfica parte-se do princípio que existem softwares no formato livre para suprir as necessidades avaliadas. Considera-se também que em caso específico do mesmo não atuar de forma satisfatória, há softwares com licenças que são por apenas algum detalhe não-livres, mas que garantam os preceitos básicos da liberdade de uso empresarial, licença sem ônus e direito de distribuição, abrindo assim uma gama considerável de softwares à disposição para a implementação.

Com base na negociação para a realização da pesquisa, a análise e diagnóstico realizados se converteram em sugestões de mudanças para a cooperativa. Dessa forma, confrontando os processos apurados como insatisfatórios supra citados e as possibilidades existentes no mercado, foram propostos softwares que realizassem as seguintes funções:

- Identificar os compartilhamento dos arquivos e pastas na rede;

- Ajustar os compartilhamentos existente e criar novos;

- Requerer e entregar/divulgar arquivos, provavelmente um programa de mensagens instantâneas que suporte envio de arquivos;

- Proteger as máquinas quanto a vírus e outras pragas virtuais;

- Executar cópia de segurança dos arquivos importantes;

- Gravar as cópias de segurança em DVD;

- Verificar se apenas usuários autorizados acessam a rede wireless.

Foram então selecionados os seguintes softwares, identificados de acordo com os objetivos que cada um deve alcançar para a melhoria dos resultados Ca cooperativa:

Objetivo 1 - Melhoria do compartilhamento de arquivos, possibilitando permitir o acesso a informações relevantes aos usuários interessados, e impedir o acesso a informações confidenciais;

Software: Share Enum 1.6.

Funcionalidade: Varre a rede em busca de compartilhamentos e permite alterações de permissão ou negação de acesso a todos eles.

Ação relacionada / utilização: Executá-lo para realizar uma série de modificações em busca de: bloquear o acesso ao servidor, porém o servidor deve acessar todos para realizar o backup. Os dois computadores da secretaria devem se compartilhar totalmente. A biblioteca deve ter acesso a algumas pastas específicas. Os demais computadores apenas às pastas compartilhadas à rede toda. Algumas pastas serão compartilhadas universalmente: uma pasta chamada TEMP apenas para transporte de arquivos e duas pastas para os coordenadores que não têm computadores próprios, porém orientados a não armazenar nelas arquivos que exigem algum tipo de sigilo. Demais compartilhamentos devem ser cancelados.

Objetivo 2 - Possibilitar a requisição e entrega de arquivos entre usuários, ou mesmo facilitar a trocar informações sem que o funcionário tenha que deixar o departamento.

Software: AChat v0.150 beta7.

Funcionalidade: mensageiro instantâneo que permite transmissão de arquivos, independe da internet, engloba apenas a rede interna e dá acesso a todos, bastando apenas digitar o nome na tela do programa para identificar o usuário que trabalha no computador. 
Ação relacionada / utilização: Instalação em todas as estações de trabalho.

Objetivo 3 - Maximizar a segurança contra pragas virtuais

Softwares: ClamWin Free Antivirus 0.93.1 e Spyware Terminator 2.3.0.481.

Funcionalidade: O ClamWin Free Antivirus 0.93.1 é capaz de detectar vírus e outros arquivos maliciosos, porém não possui proteção em tempo real, exigindo a varredura manual de arquivos suspeitos. Para tornálo uma solução efetiva, há a integração ao software spyware Terminator 2.3.0.481. Esse último não se trata de um software livre, mas sim um freeware para uso empresarial. Essa união resulta na capacidade extra de detectar spywares e execuções de processos estranhos ao sistema.

Ação relacionada / utilização: Tornar o sistema de informação mais seguro, instalando os programas em todas as estações de trabalho, menos no servidor que conta com um firewal/ próprio.

Objetivo 4 - Realizar cópias de segurança frequentemente.

Softwares: Cobian Backup 8.4.0.198 e InfraRecorder 0.45.0.0

Funcionalidade: O Cobian Backup tem agendamento próprio, o que possibilitará sua execução automática em horário predefinido, copiando os arquivos essenciais em toda a rede para uma pasta especificada no servidor. Feito isso, o próprio programa executa o InfraRecorder, que grava a cópia em DVD.

Ação relacionada / utilização: Agendamento para uma cópia de segurança semanal. Identificação das informações importantes contidas em cada computador da rede para inclusão no backup. Utilização de um DVD regravável com capacidade para 4.7 Gigabytes. Bastará concluir a gravação do DVD ao final do dia.

Objetivo 5 - Verificar segurança da rede sem fio.

Software: Network Chemistry Roguescanner 2.5.0

Funcionalidade: Verifica quais computadores estão conectados à rede sem fio e mantém um arquivo detalhando tais conexões.

Ação relacionada / utilização: Execução constante para verificação da segurança da rede e observação do arquivo de acessos. Também auxilia na conexão de novos dispositivos móveis.

Segue em apêndice a descrição completa dos programas adotados com sua respectiva tela principal e endereço eletrônico onde foi realizado o download (vide apêndice B).

Através do uso desses softwares e realização das ações ligadas a eles, espera-se que a empresa ganhe aumento da eficiência operacional e da produtividade individual dos funcionários, total segurança para seus bens de $\mathrm{Tl}$ e informações contidas neles, maior sinergia nas atividades, e fim da utilização de softwares com registro ilegal.

Buscando um método para tornar lógica e ordenada a aplicação dos novos softwares, recomendou-se a adoção de um plano ou metodologia de implementação. Pela simplicidade e clareza, foi seguida a metodologia proposta por MEYER (2000), um modelo cascata, que foi concluído no período de aproximadamente três meses. Com base nesse modelo devidamente preenchido durante a implementação, foi obtido um relatório completo de todos os passos que compreenderam o esperado bemsucedido setup dos softwares, enriquecendo a proposta com um plano de implementação completo e realizado.

\section{Considerações Finais}

A pergunta que orientou este trabalho foi: Os SL podem melhorar a eficiência dos sistemas de TI a um custo baixo? Outros questionamentos buscaram solucionar objetivos secundários: Até que ponto esses programas são confiáveis? Seu desempenho pode ser superior a um software que normalmente demanda alto investimento? Esse cenário livre está realmente pronto para entrar nas organizações? Sobre quais 
processos esses softwares podem operar? Buscou-se responder a essas questões por meio de duas análises: a viabilidade de gerenciar a informação através do software livre (1), e através dessa verificar a possibilidade de utilizar o software livre em todo o âmbito organizacional (2).

Pode-se concluir que o gerenciamento da informação através da Tl traz à empresa benefícios perceptíveis com relação à maior dinâmica e velocidade. É perceptível como a informação bem gerenciada melhora o fluxo de trabalho e, o rendimento individual do colaborador acelera os processos cotidianos, trazendo segurança para o sistema de informação, condição indispensável no momento atual que exige empresas cada vez mais conectadas e interativas.

No estudo de caso da cooperativa pode-se destacar o aumento da sinergia interdepartamental, maior dinamismo nas atividades por conta da eficiente obtenção das informações, e maior confiabilidade no sistema de informação no que se refere à segurança. Quanto aos SL pode-se observar claramente que não levam nenhuma desvantagem frente aos softwares proprietários. Com relativa facilidade é possível encontrar programas que desempenhem as mais diversas funções, atuando com qualidade, licença gratuita e código fonte disponível para possíveis alterações. Tais softwares são concebidos e desenvolvidos por pessoas decididas a tornar seus ideais públicos, abrindo uma gama de possibilidades, versões diferentes de um mesmo programa, atualizações e complementos, todos livres.

Mesmo entre os poucos segmentos de softwares proprietários que ainda não possuem SL à altura, como é o caso dos antivírus, torna-se clara a constante evolução -, embora às vezes lenta por falta de incentivo e, principalmente a próspera criação de novas alternativas. Devidamente selecionados e testados, é possível utilizá-los sobre os processos mais comuns presentes nas empresas e, com toda certeza, no gerenciamento da informação. Tal gerenciamento não envolve necessariamente softwares específicos, porém seu auxilio é de grande valia. No caso desse trabalho corresponderam ao foco central das mudanças e tiveram, sem dúvida, o desempenho esperado.

Em relação ao uso ainda pouco difundido podem-se encontrar três fatores:

- Desconhecimento de suas particularidades e conseqüente desconfiança de sua procedência e desempenho;

- Descrença da lucratividade que envolve os sistemas livres, não com venda de licenças, mas com assistência e consultoria;

- O não atendimento de necessidades específicas da empresa, por não ser projetado sob medida às suas necessidades.

Fica evidenciada como positiva a viabilidade de estender o SL a todo o sistema de informação da empresa estudada, diante da aprovação dos que que foram implementados e da facilidade do sistema em se adequar às mudanças. Seria viável a migração do sistema proprietário pelo SL, de forma gradual, embasado no fato das configurações de software serem básicas. Portanto, é viável creditar como forma de melhoria a substituição dos navegadores de internet, clientes de e-mail, mensageiros instantâneos, gravadores de CD/DVD, programas gráficos e pacotes de escritório, que são as necessidades da empresa, por alternativas livres; e posteriormente, porém com resultado mais drástico, o sistema operacional.

Investir em informação é investir em um ativo de enorme importância para a empresa. A tecnologia livre representa pouco investimento em troca de grandes resultados, contudo, ainda levará muito tempo para as empresas acreditarem nessa solução. É evidente que cada caso é único e não se pode generalizar a partir de um estudo de caso, mesmo que eles tenham sido bons, os resultados de uma empresa para outra. Entretanto, na era da informação que vivemos, se buscam vantagens competitivas, e o conhecimento é responsável por criar e alavancar possibilidades de se obter essa vantagem. Por isso, criar um sistema de informação baseado em softwares a um custo zero que promova informações rápidas e seguras aos usuários é um objetivo a ser perseguido.

A utilização de SLs demonstrou ser, no caso estudado, uma aplicação eficiente, com resultados positivos e de baixo custo. A maior contribuição deste trabalho foi demonstrar um caso de análise, diagnóstico e solução como um todo. Metodologia que foi utilizada, sem preconceitos, cujas soluções constituem uma contribuição para o campo gerencial.

Num período em que há muitos esforços sendo empregados para converter o conhecimento tácito em explícito, em que a era do acesso cria um novo grupo de excluídos digitais, a utilização de sls demonstra 
ser uma alternativa viável, pois, amplia as possibilidades de trabalho, e não restringe demais as oportunidades de acesso à rapidez e à tecnologia.

Este trabalho ainda sugere um estudo específico sobre o quarto passo, que se refere ao gerenciamento da informação, condizente à utilização da informação, que se analisaria a importância do fluxo de trabalho individualmente. Pretende-se assim, realizar um estudo mais aprofundado acerca da importância da segurança dos sistemas de informação, que apresenta preocupação equivalente ao avanço das formas de conectividade entre empresas e colaboradores, no entanto, os resultados foram animadores.

A utilização de SLS mostrou assim, ser uma alternativa viável e de fundamental importância, contribuindo para a criação do conhecimento, e sua disseminação, bem como, facilitando seu gerenciamento.

\section{Referências}

ALENCAR, A. F. A pedagogia da migração do software proprietário para o livre: uma perspectiva freiriana. 2007. 255f. Dissertação (Mestrado em Educação) - Universidade de São Paulo, São Paulo, 2007.

BIO, S. R. Sistemas de informação - um enfoque gerencial. São Paulo: Atlas, 1985.

BOAR, B. Tecnologia da informação - a arte do planejamento estratégico. 2. ed. São Paulo: Berkeley, 2002.

BRUNER, C. M.; RAWI, A. Private capital and public policy: standard; poor's sovereign credit ratings. Harvard Business School, case 9 - 705-026, 2005.

CRUZ, T. Sistemas de informações gerenciais - tecnologia da informação e a empresa do século XXI. São Paulo: Atlas, 1998.

FGV - FUNDAÇÃO GETÚLIO VARGAS. Estudo sobre o software livre. Rio de Janeiro: Presidência da república, Casa Civil, Instituto Nacional de Tecnologia da Informação, 2005. Disponível em:

<http://www.iti.gov.br/twiki/pub/Main/Dta/Estudo_FGV.pdf>. Acesso em: 21 jun. 2008.

FREE SOFTWARE FOUNDATION. The free software definition. Disponível em <http://www.fsf.org/licensing/essays/free-sw.html>. Acesso em 21 jun. 2008.

GIL, A. C. Como elaborar projetos de pesquisa. 4. ed. São Paulo: Atlas, 1999

GNU. El sistema operativo GNU. Disponível em <http://www.gnu.org/home.es.html>. Acesso em 28 jun. 2008.

GUIA LIVRE. Referência de migração para software livre do Governo Federal. Versão 1.0. Brasília: 2005. Disponível em: <http://www.governoeletronico.gov.br/anexos/E15_469GuiaLivre-v1-02.pdf>. Acesso em: 21 jun. 2008.

KÜSTER, E. Metodologia para a organização do processo operacional das empresas de pequeno porte, visando a implantação de sistemas de informação. 2001. 124f. Dissertação (Mestrado em Engenharia de Produção) - Universidade Federal de Santa Catarina, Florianópolis, 2001.

LUCAS, H.; SWANSON, E B.; ZMUD, R. W. Implementation, innovation, and related themes over the years in information systems research. Journal of the Association for Information Systems. v. 8, n. 4, p. 206-210, 2007.

MACAN E. M.; ALMEIDA R. Q. Por que usar software livre?. Disponível em:

<http://www.ccuec.unicamp.br/revista/infotec/linux/linux12-1.html>. Acesso em 12 jul. 2008.

MATTOS, J. R. L.; GUIMARÃES, L. S. Gestão da tecnologia e inovação - uma abordagem prática. São Paulo: Saraiva, 2005.

MEYER, M.; BABER, R.; PFAFFENBERGER, B. Nosso futuro e o computador. 3. ed. Porto Alegre: Bookman, 2000.

OLIVEIRA, D. P. R. Sistema de informações gerenciais: estratégicas, táticas, operacionais. 6. ed. São Paulo: Atlas, 1999. 
OLIVEIRA JR., Z. G.; CASTRO, D. S. P. Gestão estratégica da tecnologia de informação em uma instituição de ensino como diferencial competitivo. In: ENCONTRO NACIONAL DOS PROGRAMAS DE PÓS-GRADUAÇÃO EM ADMINISTRAÇÃO, 30, 2006, Salvador. Anais... Rio de Janeiro, ANPAD, 2006.

PEREIRA, M. F. F. Gerenciamento da Informação: um diagnóstico da micro e pequena empresa industrial de Londrina. 2003. 154f. Dissertação (Mestrado em Engenharia de Produção) - Universidade Federal de Santa Catarina, Florianópolis, 2003.

SANTOS, L. G. dos. Melhoria do gerenciamento da informação em uma instituição de ensino através da implementação de softwares livres. Monografia (Curso de Graduação em Administração). 2008. Universidade Camilo Castelo Branco - Unicastelo, Descalvado/SP, 2008

SORDI, J. O. Tecnologia da informação aplicada aos negócios. São Paulo: Atlas, 2003.

TAKAHASHI, T. (Organização.). Sociedade da informação no Brasil: livro verde. Brasília: Ministério da Ciência e Tecnologia, 2000.

WHYTE, W. F. Sociedade de esquina: a estrutura social de uma área urbana pobre e degradada. Rio de Janeiro: Jorge Zahar, 2005.

YIN, R. K. Estudo de caso: planejamento e métodos. Porto Alegre: Bookman. 2001. 